\section{Doubts over new degree courses}

Washington

WHILE biotechnology has long since won the confidence of investors, it is only just beginning to appear as a degree subject in its own right. This fall, several two- and four-year programmes will emerge. Lacking precedent or prototype, their curricula are intended to meet industry's needs. But industry, which is not at present grappling with a labour shortage, is greeting some of the programmes with ambivalence.

Although programme designs vary some common threads run through them all. They tend to be long on chemistry, mathematics and biology, but short on electives. They will be counted among the most difficult degrees offered at most institutions. They will also be expensive: one state-subsidized programme costs about $\$ 10,000$ per student for one semester, but charges only $\$ 780$ tuition.

Above all, biotechnology programmes emphasize technical proficiency and hands-on experience. Students will become adept with protocols and equipment they would not ordinarily encounter until graduate school. "To my mind, biotechnology isn't a discipline in itself", says Jean Brenchley, who heads the new biotechnology institute at Pennsylvania State University. "I see it building upon traditional disciplines, and the techniques are what serve as the focal point."

The university recruited Brenchley from Genex Corporation in 1984 to direct the institute's research activities, but students encouraged her to devise a degree programme as well. Penn State's programme brings many different departments under the umbrella of the $\$ 7$ million biotechnology facility which will be complete this winter. Engineers will be expected to learn about the metabolic requirements of microbes, and molecular biologists will be taught to think about large-scale production.

Brenchley's curriculum represents one of the two approaches to biotechnology training. Her graduates will be groomed for $\mathrm{PhD}$ programmes or research and development laboratories with starting salaries around $\$ 25,000$. In contrast, other academics are aiming at a still-nascent niche for the production and quality control technician who would require less theoretical education and would ultimately receive a smaller salary. In order to assess the opportunity for such positions, 10 two-year colleges in the mid-west last year commissioned a report from the Center for Occupational Research and Development in Waco, Texas.

The projections were rather optimistic. Pooling the responses of 86 companies in the industry, the report predicts that the number of US biotechnicians will increase by 148 per cent by 1995 . That means 1,000 new job openings per year for people with associate degrees in biotechnology.

Industry, while expressing enthusiasm for bachelors' programmes, seems sceptical that two years in college can provide the knowledge necessary to manage complex instrumentation and sensitive organisms. Michael Montague, director of Monsanto's biological sciences division calls the Waco centre's 1,000 a year projection "definitely a guess". Others fear that technicians who lack theoretical understanding may also lack the flexibility to adjust to a rapidly-evolving technology. And they acknowledge that two-year programmes bear a stigma in an industry where many of the executives are PhDs.

Associate degree programmes may face a barrier more intractable than industry prejudice - cost. The equipment, supplies and faculty necessary to teach stateof-the-art techniques can carry prohibitive price tags. Some more seasoned four-year programmes have hit upon money saving solutions.

Industry contributions, for example, can take the edge off equipment expenditure. At the Minor Institute in Chazy, New York, many of the laboratory expendables for an intensive one-semester programme in biotechnology are gifts from the manufacturers, who hope to "hook" students on their brands. Academic coordinator William Graziadei, who forged the link between Minor and Plattsburgh State, developed a network of adjunct professors that brings 35 industry and academic experts to the remote university town each year, yet keeps the programme's payroll down to a minimum.

In Seattle, Washington, local colleges have established a tradition of work-study projects with nearby Immunex. Laboratory manager Carol Ranthum says that about 15 of the company's 140 staff members are students who work 10 to 20 hours a week; the state pays two-thirds of their salaries. Immunex has hired five graduates of the programme since 1982 . In addition to saving money, work-study arrangements and adjunct professorships also serve to remedy the threat of stagnation that plagues any high-tech curriculum.

Ultimately, however, employers seem to value experience as highly as either two or four years of education. "The more skills you can bring in that don't have to be taught, the better off you are", says Pioneer Hybrid's biotechnology research director, Nick Frey. By combining experience with education, biotechnology degree programmes are bound to ensure that tomorrow's graduates have at least a little more laboratory finesse than today's.

Karen Wright
Climatic research Wind of change
in Washington

Washington

AN unlikely alliance between environmental activists and former government officials has been formed to warn decision-makers and the general public about the serious climatic changes that many scientists now predict could occur within the next 100 years. The Climate Research Institute, based in Washington DC, plans to publish a newsletter giving non-technical summaries of research results and to organize conferences on the effects of climate change for constituencies such as coastal communities and agriculture.

The institute says there is a "solid scientific consensus" that a perceptible global warming due to an enhanced greenhouse effect will soon be apparent, and that an

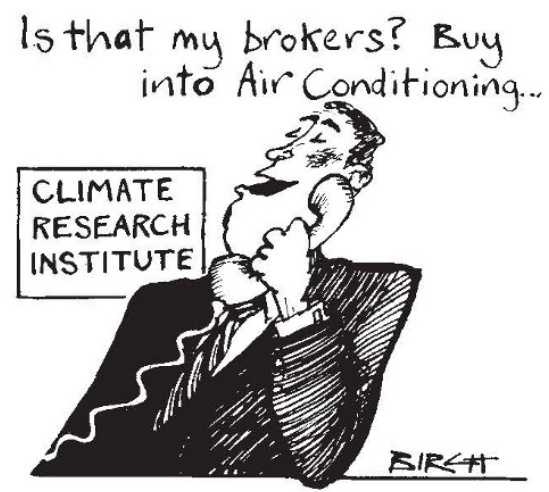

increase of $5^{\circ} \mathrm{C}$ is a reasonable prospect by the middle of next century. The institute's president, John Topping, a lawyer who was formerly staff director of the Environmental Protection Agency's office of air and radiation, says the institute was created to draw public attention to such projections and to put them high on the public policy agenda. He points out that only 9 out of 12,000 employees of the Environmental Protection Agency are working full time on climate change.

The institute's board includes former officials from both the executive and the legislative branch, as well as luminaries from the environmental movement. It will sponsor discussion and, Topping hopes, some policy research both on means of delaying climate change and on means of mitigating its consequences. The institute may, for example, pay researchers' expenses to visit Washington to address government officials, and it hopes to organize national and international conferences on selected aspects of climate changes.

As yet, the institute cannot afford to pursue all these avenues, but Topping is hoping that current approaches to corporations and charitable foundations will reap rewards.

Tim Beardsley 